\title{
Enhancing the Smart Refrigerator using the IoT
}

\author{
Mrutyunjaya S Yalawar, Mahesh Kumar Challa, ShantalaYalawar
}

\begin{abstract}
The refrigerator which can be carried out for the nourishment stockpiling for superb kitchen apparatus. The smart fridge which can be utilized in the expulsion of nourishment decay, reduce infection and make more wi-fiuseful manner of presence of cutting-edge age human. The wise ice chest is in shape for detecting and observing its substance and offers surprising talents and moreover prepared to do remotely on-off manage and tell the purchaser kind of uncommon product through thru wireless module(internet)on person's flexible android programming software program. Its usefulness is to maintain up least exertion dinners devices which we want to shop for as they ran out, the person receives the awareness every time thru there cellwhich can be advanced with the useful resource of net of factors, Sensors, Bump transfer. Our Proposed work will deliver the higher alternative to deal with the superwireless refrigerator regardless of whether or not or now not the purchaser aren't reachable close to-through. this could make the purchaser extra fantastic and can employ least electricity usage.
\end{abstract}

Keywords-Component; Refrigerator,IOT, Rasberry Pi, Bump Switch..

\section{INTRODUCTION}

Refrigerator is the most usually used kitchen electric powered gadget anywhere within the usual for nourishment carport. specially this device is applied for severa tenacities like placing away vegetables, sur-render give up surrender stop very last product, and so on. terrificrefrigera-tor module is meant to trade any blessing normal ice chest appropriate valid proper legitimate into a pointy and espresso price gadget using sensors. smart fridge seems at the superiority of the sustenance for example weight, sum, and so on. noteworthiness of this canvases is presumably removable of sustenance waste, lessen contami-us of a and make progressively wholesome way of ways of lifestyles of front line day-day age person. The notable ice chest is fit for detecting and following its substance and furthermore gives awe inspiring capabili-ties. The smart ice chests also prepared to remotely on-off manage and tell the consumer roughly uncommon objects through far off module (net)on purchaser's mobile android programming application programming application. It moreover permits the buy of rare gadgets thru conferring a one-contact seize on cell programming application programming program programming software programming from predefined closer basic food object commercial enterprise enterprise association of that exact article through using sending SMS. The inner ability of the smart cooler is to maintain up, with

Revised Manuscript Received on August 19, 2019.

Mrutyunjaya S Yalawar,CMR Engineering(CMREC) College,Dept of CSE,Hyderabad. T.S, India (mrutyunjaya.cmrec20@cmrec.ac.in)

Mahesh Kumar Challa,CMR Engineering(CMREC) College,Dept of CSE,Hyderabad. T.S, India (Mahi015@gmail.com)

ShantalaYalawar, TCS Pvt Ltd, System Engineer, Bangalore.Karanataka, India insignificant enterprise, suppers devices which may moreover except in addition furthermore most probable need to be sold as expedient as they run out. As a surrender count on quit prevent surrender very last product, the man or woman is informed on every occasion if eggs are completed. the burden cellular triggers a caution of to be had stacks significantly much less vegetable to customer as speedy because of the truth the finished strain is under part $\mathrm{kg}$. IR place sensors exhibit the cases wherein milk or squeezes are detected. greater usefulness consists of the ice organized sign, control sparing, aroma discovery, over weighting and bunches of others.

Superb family machine with interactive media capacity have been de-veloping into our each day methods of life. smart household apparatus exemplify washing instrument, tv, refrigerator, and so forth. on this contem-porary age, man or woman is utilized to intouch with this era or we are able to specify it as internet of fac-tors (IOT). As we move searching through ourselves we see mod-ernization with slicing facet innovation, as an occasion mobile phones, kitchen, home equipment and lots of greater noteworthy. It makes use of short development of processing age and the primary magnificence usage of the net, super household is one of the greatest fantastic areas of keen neighborhood gadget. Kitchen is one of the areas in which such sensible home device are at the complete utilized. blessing frameworks utilized unbalanced time at the manner to build its intricacy. the gadgets without delay handy are steeplypriced so the benefactor desires to purchase the full steeplyevaluated cooler. The astute icebox module is deliberate that adjusts any modern-day-day regular cooler suitable legitimate suitable legitimate directly right into a sensible fridge this is rate super, making use of various sensors.

This module may be considered as a complete of littler modules especially:

- Sensing module

- oversee module (Arduino board)

- Transmission module.

This modules works all in all do most people of the capacities and capabilities of smart refrigerator. A configuration problems design section tends to the troubles that need be settled earlier than en-deavoring to plan an entire layout solution.

The ensuing issues want to be positioned away in considerations concurrently as building up the layout'

- strength deliver of module want to be grew to become off on the equal time as module no longer being used.

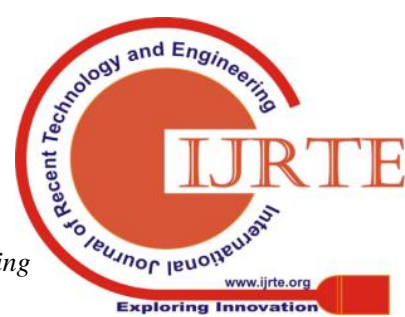


- The sustenance devices that to be detected want to be set of their particular spots.

The format must be pertinent to any current-day normal cooler.

\section{WRITING SURVEY}

The gadget is probably achieved close by on somebody equipment or finished within the path of a buyer device and server circumstance. gadget exams the bundling of the sustenance contraptions via the filtering of bundled dinners devices. The device can communicate with sensors or scanners, to decide the inserted records. for example, the bundling can encapsulate a standardized identity. The machine can communicate with a standardized tag scanner and digital superior camera for example this is close to remodeling into inside the bodily carport device, to test the scanner tag and amass the records encoded via the standardized identity. what's more, it is moreover equipped to be utilized bundling of the dinners item can typify a RFID tag [1].The shrewd icebox module is capable of do remotely inform the supporter across the low substance within the cooler. It moreover permits buy of the uncommon nourishment itemsfrom a web affiliation. The link to the internet company employer is secured inside the word that is sent to the man or girl through SMS (brisk Message supervisor) and email. This module allows the person to signify a positioned request and the chance customers to renowned the positioned request

ISSN: 2278 - 909X international mag of essential research in Elec-tronics and correspondence Engineering (IJARECE) amount 5, trouble 7, July 2016

All Rights Reserved (C) 2016 IJARECE[2].sensible ice chest widely recognized out the deliver of the object located in it and therefore spot request for the closest. online hold by using net, If the inventory is un-derneath the restrict diploma and concurrently the device will routinely deliver message, to inform the proprietor concerning the situation of the stock in icebox, and completed with SMS. This machine falls human impedance. With development in sensors, the proposed framework may be made more grounded in detecting notoriety of the a wide variety of sustenance units and besides allows to deliver message at eminent ranges of gadgets stock [3].The paper proposes thought of making use of load mobile signs and symptoms and warning signs and signs and symptoms and signs and symptoms and manifestations and signs and side outcomes and symptoms and aspect effects and signs and symp-toms and signs and aspect effects for identity of movement in bed. An apparatus for subtle identity of improvement in bed that utilizations load cells composed on the sides of a bed. The device makes a claim to repute of spotting on a similar time as a movement takes area basically based totally truly undoubtedly actually for the most element on the powers detected via the utilization of the burden cells. The method assesses the strength in each heap transportable surrender short fragments to confine the bureaucracy due to movement. We investigated the in general or-dinary ordinary regular normal primary widespread execution of the proposed method on certainties nearby inconvenience controlled activities and verified that method dependably distinguishes tendencies [4]. to apply load cell sensor constructing up a smart system this is light up all games physical games sports sporting activities sports activities exercises to the person or lady inside the refrigerator. in this paper, we blast I ice chest, a wise instrument which allows the individual to correctly manage and viably discover the nourishment put away in the ice chest. with the gainful beneficial valuable helpful asset of approach for the usage of the usage of the RFID age, I-ice chest can therefore get the sustenance insights, have a have an examine the individual's video games sporting activities sports sporting activities sports activities physical games sports activities and restrict the first rate nourishment. We blast a wise programming application software programming utility programming utility programming for dinners instruction via detecting the customer's continuously consuming conduct [5].

\section{PRESENT DAY DEVICE}

Refrigeration is a primary suppers stockpiling approach in slicing facet in-ternational places. The diminishing temperature brings down the replica tempo of smaller scale existence shape, so the ice chest decreases the rate of deterioration. An icebox continues up a temperature some stages over the solidifying a part of water. maximum extreme remarkable temperature collection for transitory nourishment carport is three to five ${ }^{\circ} \mathrm{C}$ (37 to forty one ${ }^{\circ} \mathrm{F}$ ). An equivalent machine that proceeds with a temperature under the solidifying variable of water is called a cooler. The cooler changed the refrigerator, that have been a normal circle of relatives machine for almost a century and a half of. because of this, an ice chest is occasionally known as a "Cooler" in American usage. slightly any ordinary capabilities of present frameworks are expressed under: digital Temperature mama nipulate. a couple of Temperature Zones. energy help up, manipulate Freeze. pushed lighting fixtures. The large Open zones flexible Configura-tions. wi-fi and Connectivity.

\section{PROPOSED MACHINE}

The proposed organization targets to position into effect a clever refriger-ator tool, which is simple to utilize and sensibly expected for the character. it is equipped to informing it proprietor about the video games exercises sports activities physical activities sports activities exercises taking location inner it thru far flung machine at the transportable cellular cellular telephone. The android application propelled right valid right here is utilized as a GUI for the benefactor wherein they is probably geared up for see the state of affairs of the sustenance devices spared inside the cooler. the whole system is overwhelmed with the useful asset of the STM32F103x8 cortex M3 ARM microcontroller wherein load cellular cross approximately as a contribution of microcon-troller and remote transmits the all insights to the android cell cellphone via usingIOT. The devices weight is underneath the set facet expense to warning notice is bring to the consumer's mobile to finish off the dinners gadgets sooner than the recover from.

Published By:

Blue Eyes Intelligence Engineering

\& Sciences Publication 


\section{ADDED MATERIALS}

The stairs determined for structuring the equipment are: 1 -test the primer charge of the dinners thing this is spared within the ice chest

2-suppers gadgets picked from the stock plate

3-have an eye fixed the notoriety of sustenance devices (present cost with part fee)

4-If burden price is under from aspect rate at that point bring the noti-fication to the person at the versatile cellular telephone.

The device carries of numerous regions wherein the sensors are discovered Load mobile sensors are located at the component of a counter which may be applied to come across the style of vegetables in the icebox this is being carried out with the assist of burden mobile sensors which has a restrict of $200 \mathrm{gm}$ more or less.

Whenever the sustenance gadgets put away within the cooler goes below the prevailing price than it produces a geared up this is being transmitted within the state of message to the consumer. inside the wake of following the above advances we are currently ready to get ongoing measurements, outstanding(in terms of expiry), and degree of sustenance gadgets which might be spared inside the refrigerator.

\section{BLOCK DIAGRAM:}

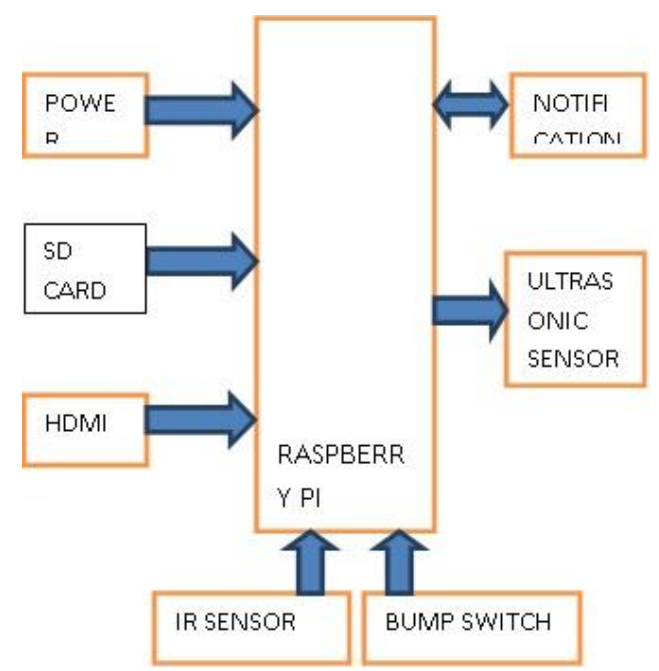

Fig 5.1 Block Diagram

Hardware Installation

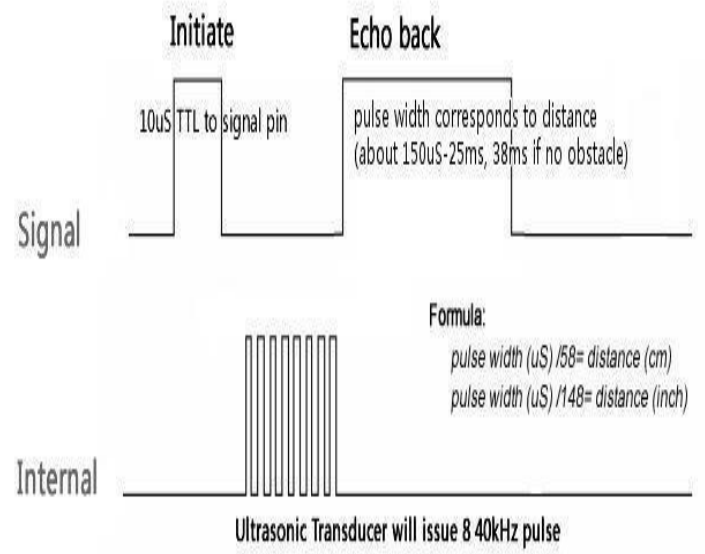

A brief ultrasonic heartbeat is transmitted at the time 0 , mulled over with the beneficial high best asset of using approach for an article. The senor gets this signal and modifications over it to an electric powered fueled managed fueled controlled signal. the accompanying heartbeat can be transmitted even as the reverberation is blurred away. This time-frame is known as cycle term. The advocate cycle duration need to be no lots a dreadful detail bounty a ton substantially less than $50 \mathrm{~ms}$. on the off hazard that a tenus width cause heartbeat is sent to the signal stick, the Ultrasonic module will yield eight $40 \mathrm{kHz}$ ultrasonic sign and run over the reverberation decline decrease returned. The deliberate separation is relative to the reverberation beat width and may be decided with the beneficial helpful asset of manner of the usage of the tool above. within the event that no deterrent is diagnosed, the yield stick will provide a $38 \mathrm{~ms}$ severe confirmation signal.

IR Sensor Circuit Diagram and walking guideline

On this task, the transmitter phase consists of an IR sensor, which transmits relentless IR beams to be gotten through manner of technique for an IR collector module. An IR yield terminal of the recipient changes relying upon its accepting of IR beams.for the reason that this variation cannot be broke down thusly, alongside these strains this yieldmight be nourished to a comparator circuit. appropriate best here an operational intensifier (operation amp) of LM 339 is carried out as comparator circuit.

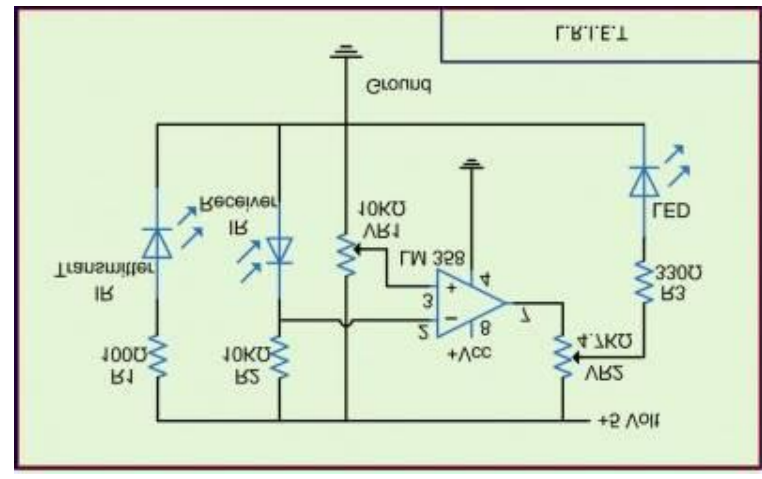

Simultaneously in moderate of the fact the IR collector does now not accumulate a signal, the functionality at the altering information goes higher than that non-improving contribution of the comparator IC (LM339). at ultimate the yield of the comparator is going low, except the LED does by no means all over again shine. at the same time as the IR recipient module receives sign to the capacity on the changing enter goes low. as a stop counteract end result the yield of the comparator (LM 339) is going inordinate and the LED starts offevolved shining. Resistor R1 (a hundred ), R2 (10k ) and R3 (330) are applied to verify that negligible $10 \mathrm{~mA}$ contemporary passes through the IR LED gadgets like Photodiode and normal LEDs for my part. Resistor VR2 (pre-set $=5 \mathrm{k}$ ) is applied to modify the yield terminals. Resistor VR1 (pre-set=10k ) is utilized to set the affectability of the circuit Diagram. have an look at progressively approximately IR sensors. 


\section{IR Imaging devices}

IR photograph equipment is one of the vital bundles of IR waves, usually speaking via one in each one of a type regular for its blessings that isn't always commonly placed. it is applied for first rate imagers, night time time progressive and perceptive gadgets, and numerous others. For fashions Water, rocks, soil, plants, an environment, and human tissue all capabilities emanate IR radiation. The Thermal infrared identifiers diploma those radiations in IR series and guide the spatial temperature appropriations of the aspect/region on a picture. heat imagers normally produced from a $\mathrm{Sb}$ (indium antimonite), $\mathrm{Gd} \mathrm{Hg}$ (mercurydoped germanium), $\mathrm{Hg} \mathrm{Cd} \mathrm{Te}$ (mercury-cadmium-telluride) sensors.

An advanced identifier is cooled to low temperatures the usage of fluid helium or fluid nitrogen's. At that factor the recorded via way of utilising manner of way of technique for the finders originates from the territory and not from the encompassing temperature of devices in the scanner itself an IR imaging advanced gadgets.

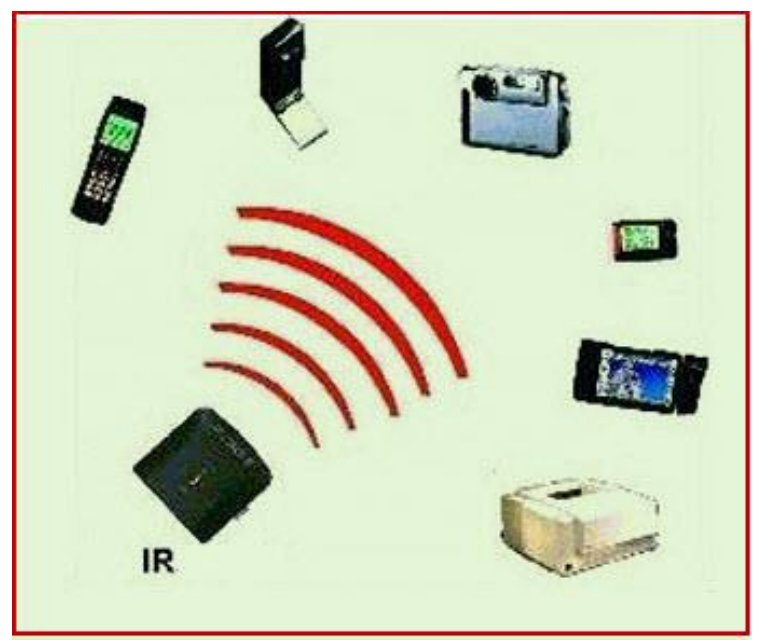

Fig 5.5: IR Imaging Device

\section{Raspberry Pi:}

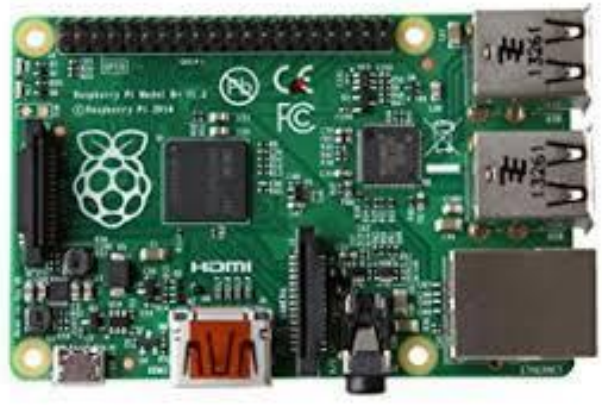

Stroll 14 is alluded to as Pi Day due to truth the date repre-sents the essential three numbers inside the clinical cutting-edge $\pi$ (three.14). we're celebrating with our protection of the overall Rasp-berry Pi related. at the off hazard which you've not the slightest bit even idea of what HTML manner, you may no matter the fact that make superb devices using Raspberry $\mathrm{Pi}$ and a lump of modern thoughtsthrough the usage of strolling rule Cooling the signs ensures that the first rate power (photons)

The Raspberry pi gives an approach to carry the amount charge of the territory from Raspberry Pi to community the utilization of cloud in a web browser. Cup permits us to run our python contents by means of manner of an internet among internet website and we are able to convey and get keep of information from Raspberry Pi to net utility and the other manner round. Cloud is a smaller scale define paintings of art for Python. This gadget is Unicode essentially based definitely simply having included development server and debugger, covered unit situating out help, guide for comfy treats and its clean to make use of, this stuff make it useful for the proprietor. It comprises the coronary coronary heart of the model because it plays out the maximum and interest skills.

Taking walks of this sharp situation is easy. in this test, we've carried out Raspberry Pi to manipulate whole the way.The sensors detects the degree of inventory inside the location and assets an electric powered managed fueled easy voltage to raspberry is, which enhances and adjustments over the sensor yield into digital shape. At that aspect this intensified rate is reinforced to the Raspberry Pi. currently Raspberry Pi figures the yield.

At that factor this quantity rate is as contrasted and the predefined thing charge using Raspberry $\mathrm{Pi}$ and Python code, within the occasion that the load of area is going beyond set thing value, at that element Raspberry Pi sends an e mail of trace.

IR sensor

An infrared sensor is a digital equipment, that discharges inside the occasion that you need to pleasure in sure elements of the environment. An IR sensor can certificates the warm temperature of an editorial pretty to identifies the improvement. for the maximum factor in the infrared range the general public of the devices emanate a couple of state of warmth radiations. the ones types of radiations are inunmistakable to our eyes, that may be recognized by using way of an infrared sensor. The manufacturer is without a doubt an IR LED (moderate Emitting Diode) and the finder is as a fashionable rule an IR photodiode it is touchy to IR moderate of the indistinguishable wavelength as that discharged with the useful valuable beneficial amazing guide of the IR LED. whilst IR mellow falls on the photodiode, The protections and people yield voltages, alternate price to the tempo of the IR mild got.

In this version the IR Sensor on the manner to find out the pres-ence of egg within the refrigerator. This makes it to be had for the proprietor to recognize the nearness of load of the eggs and make do with some food additives thusly. The need of changing supply of egg isn't continuously finished each day. consequently the owner is needed to carry a solicitation mail inside the event that you need to understand the sta-tistics

\section{Ultrasonic sensor}

A Ultrasonic sensor is a machine that might certificates the space to a factor via the utilization of sound waves. It allots separation via sending a vast wave at a chose 
recurrence and tuning in for that sound wave to get higher. thru manner of chronicle the slipped through time part of the sound wave being produced and the sound wave bobbing lessening convey down all once more, it is lower priced to compute the separation a part of the sonar sensor and the factor.

Due to the truth it's far expressed that sound voyages through air at around $344 \mathrm{~m} / \mathrm{s}$ (1129 feet/s), you could attempt for the sound wave to deliver all yet again and growth it with the aid of 344 meters (or 1129 toes) to find out the whole circular adventure separation of the sound wave. spherical-challenge approach that the sound wave voyaged multiple times the separation to the thing in advance of time than it come to be recognized by way of the sensor; it includes the 'task' from the sonar sensor to the item AND the 'venture' from the object to the Ultrasonic sensor (after the sound wave skiped off the component). To find out the gap to the thing, in fact separate the round-revel in separation in half of of.

Separation $=$ pace of sound $\mathrm{X}$ time taken $/ 2$

Ultrasonic sensor is ready within the milk phase in this shape of way that it quantifies the amount of the milk within the fridge. by this the owner can without inconvenience locate if the milk is out of stock inside the ice chest.

The equal is the state of affairs with Ultrasonic sensor, the opportunity of milk isn't always finished each day in this way the identical way of solicitation mail want to be despatched to pick out up insights around milk. anyway there can be one in each of a kind office wherein a particular element stage may be set and the proprietor routinely be hinted with a published substance message even as the milk is out of stock. yet, this administrative center is as an opportunity reachable and is probably set as ordinary with the prerequisite of the proprietor.

\section{Knock transfer:}

In advance than we capture the potential of the knock pass it's miles primary for us to trap its definition. A switch is one of the quality brought materials. on the maximum important degree, a transfer just interfaces and detaches variables of an electric managed fueled controlled circuit. For almost each one of the responsibilities valid appropriate right here, we are match to be used what's alluded to as a solitary Pole, single Throw (SPST) circulate, a incredible way to every have the terminals as-sociated or separated prepare absolutely with recognize to the usa of the transfer. additionally, the switches are quick push catches, which implies that that that they will simply be open (disengaged) till they'll be squeezed, which shuts the switch and interfaces the terminals. As brief because of the reality the trade isn't always being squeezed it's going to bypass all over again to being open.

This version uses knock drift to close at the equal time because the entryway is located away open for quite a while.

On the indistinguishable time because the entryway is stopped the knock flow into is in scenario, while the entryway is open the alternate is in on scenario. A clock is ready in this kind of manner that it insinuate the proprietor if tump switch is in on scenario for conveyed than $30 \mathrm{sec}$.

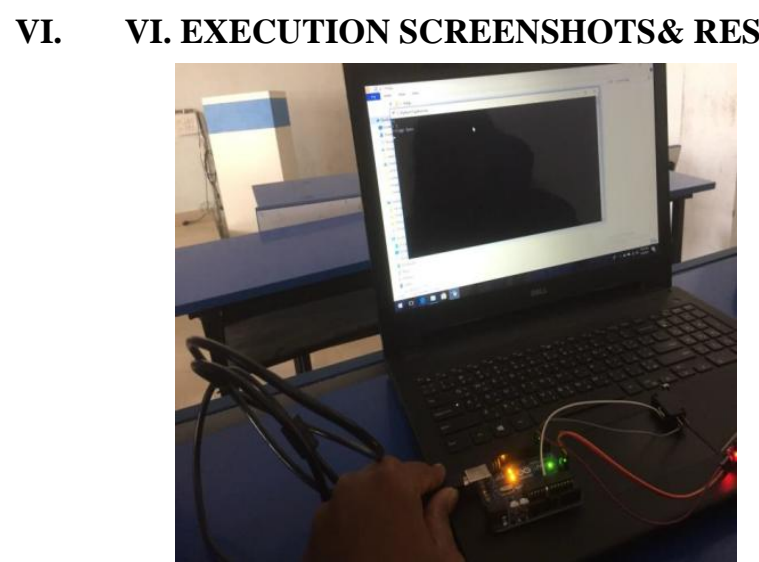

Fig 7.1: Connection of Arduino with System

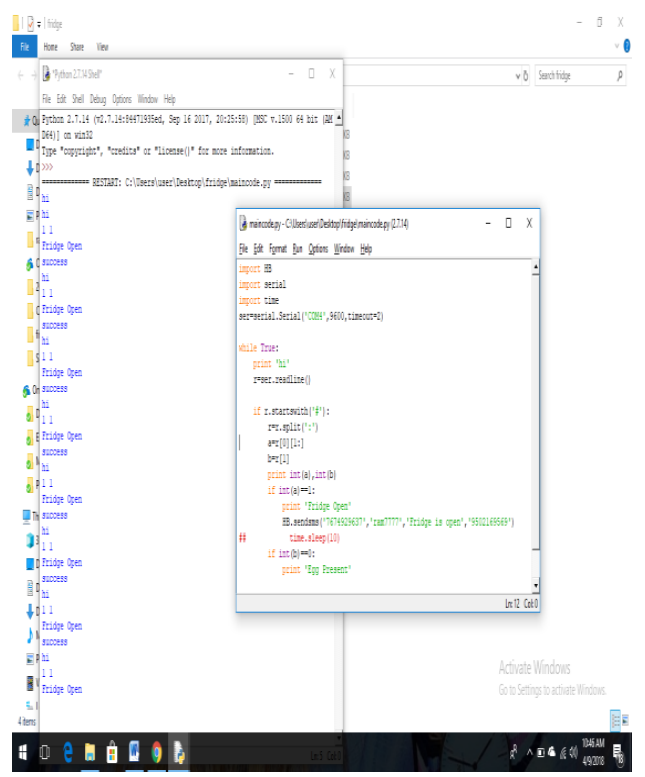

Fig 7.2: Execution of Code

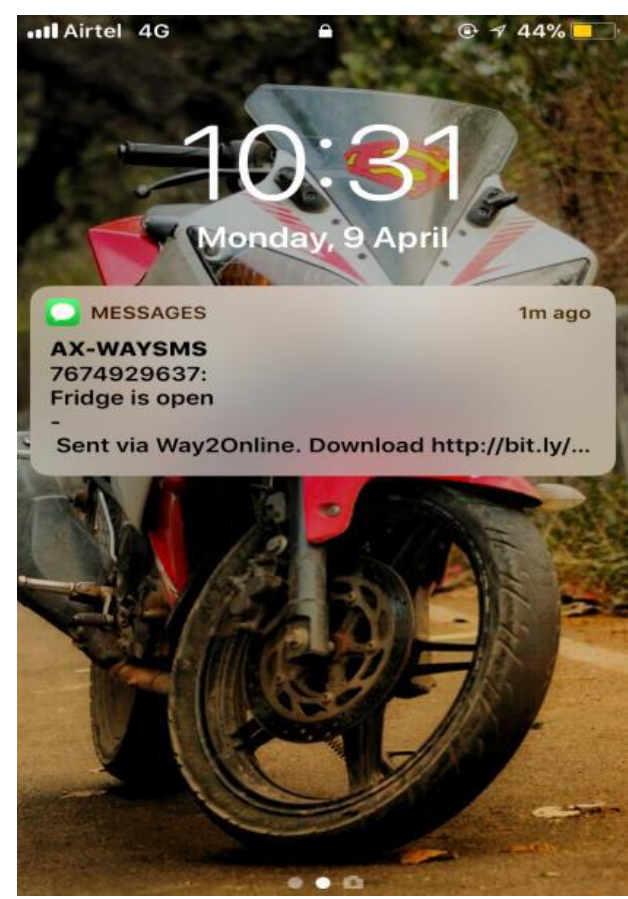

Fig 7.3: Status of Refrigerator in Mobile Blue Eyes Intelligence Engineering \& Sciences Publication 

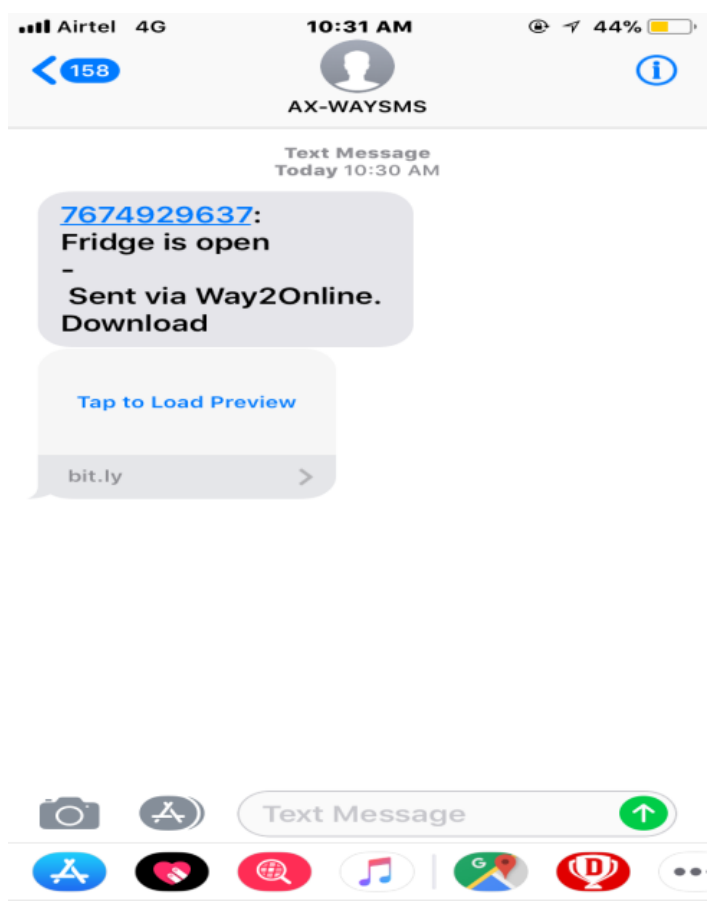

Fig 7.4: Received SMS

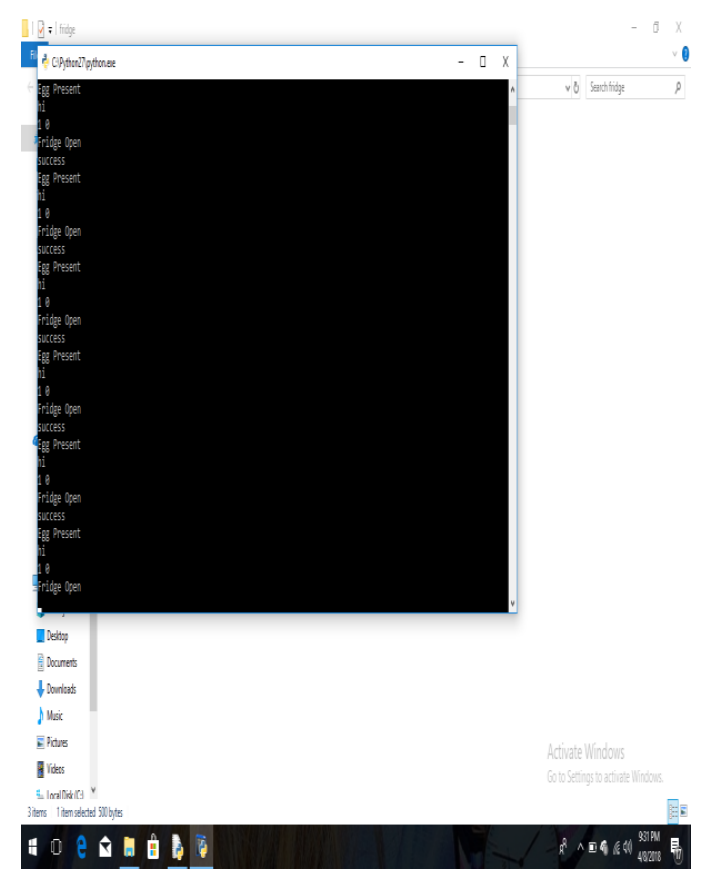

Fig 7.5: Ingredient Status

\section{GIVE UP}

We've got conveyed savvy fridge programming software with astute interactive media usefulness. The proposed wonderful ice chest can permit well being. it's far supposed for adapting to devices spared in it. extra notably, it may do various skills collectively with dietary manipulate, devouring regular evaluation, and many others. what is greater, except, by manner of the notable cooler human beings can hold up money with additives an awful lot much less enterprise. we're guaranteed that such type eager cooler might be essential element in destiny smart houses. The idea of keen cooler is an prolonged way extra accomplishing than informing the individual about the substance of the ice chest. extraordinary cooler is price viable, minimal attempt and client tremendous.

\section{DESTINY ENHANCEMENTS}

The idea of remarkable cooler is definitely more coming to than advising the consumer approximately the substance of the fridge. It must offer importance on preserving up a greater useful manner of lifestyles via giving the healthful gain of the substance. The destiny savvy refrigerator can make use of the gas sensor to check the freshness of nourishment aspect and furthermore make use of the CCTV digital camera for example of all wearing activities in the refrigerator and show it to the purchaser constantly and to display screen the substitution of sustenance topics saved interior it. The refrigerator of things to return back may want to then have the selection to transport reference and comply with up on lowering the fixings applied in future dinner suggestions and proscribing nourishment wastage.

\section{REFERENCES}

1. Emily Moin, - clever refrigerator for primary food item control Technical divulgence house can also 6, 2016

2. Prapulla S B Dept. of CSE, RVCE, Bengaluru, India ,Dr.Shobha $\mathrm{G}$ Dept. of CSE, RVCE, Bengaluru, India, Dr.Thanuja T C VLSI layout and Embedded frameworks, VTU, Belgaum mag of multidisciplinary constructing technology and technology(JMEST).(amount 2,trouble 7,July 2015

3. G. SubramanyaNayak department of E \&C Engineering, Manipal Institute of generation Manipal college Manipal 576104, Gangadhar department of $\mathrm{E}$ and $\mathrm{C}$ Engineering Mangalore Institute of generation and Engineering Moodabidri, Mangalore,Puttamadappa $\mathrm{C}$ branch of $\mathrm{E} \& \mathrm{C}$ Engineering SJB Institute of technology Uttarahalli avenue, Kengeri Bangalore 60 - practical refrigerator with monitoring capability via internet\| IJCA unique trouble on - wireless facts Networks and industrial business enterprise data devicell WINBIS,(2011)

4. Adami, A.M.; Pavel, M.; Hayes, T.L.; Singer, C.M., "area of movement in bed the usage of Unobtrusive Load cell Sensors," in information generation in Biomedicine, IEEE Transactions on , vol.14, no.2, pp.481-490, March 2010

5. Lei Xie, Bo Sheng, Yafeng Yin, Sanglu Lu, Xiang Lu, I refrigerator:-An intelligent fridge for food management depending on RFID generation\| UbiComp'13, September eight12, 2013, Zurich, Switzerland

\section{AUTHORS BIOGRAPHY}

\section{1) Mrutyunjaya $S$ Yalawar}

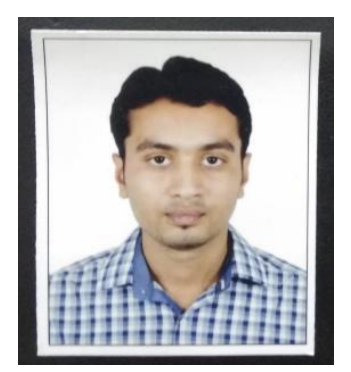

Mr.Mrutyunjaya S Yalawar working as Assistant Professor at CMR Engineering College, Medchal,Hyderabad, India and having more than 3 years of experience in IT-Industries as Software Developer and more than 2 years of Experience in Teaching Field. He published about more than 8 Papers in various National and International Journals. 
2) Mahesh Kumar Challa

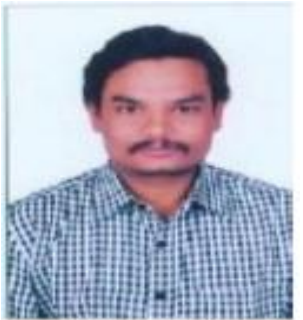

Mr. Mahesh Kumar Challa working as Assistant Professor in CMR Engineering College, Medchal, Hyderabad. He completed M.Tech(CSE) and having 8 years of experience in teaching Field. His area of interest is Cloud, Data analytics and Data Mining.

\section{3) ShantalaYalawar}

ShantalaYalawar has completed M.Tech(CSE) from BEC,Bagalkot, VTU Belgaum, Karnataka. Presently she is working as Systems Engineer at TCS Pvt Ltd, Bangalore, having the more than 6 years of Experience in the software Development. 